\title{
Maternal age and risk of cesarean section in women with induced labor at term - a Nordic register-based study
}

\section{Bergholt, Thomas}

2020-02

Bergholt , T , Skjeldestad , F E , Pyykönen , A , Rasmussen , S C , Tapper , A-M , Bjarnadóttir , R I , Smárason , A, Másdóttir , B B , Klungsøyr , K, Albrechtsen , S , Källén , K, Gissler , M \& Løkkegaard, E C L 2020 , ' Maternal age and risk of cesarean section in women with induced labor at term - a Nordic register-based study ' , Acta Obstetricia et Gynecologica Scandinavica, vol. 99 , no. 2 , pp. 283-289 . https://doi.org/10.1111/aogs.13743

http://hdl.handle.net/10138/319804

https://doi.org/10.1111/aogs.13743

unspecified

Downloaded from Helda, University of Helsinki institutional repository.

This is an electronic reprint of the original article.

This reprint may differ from the original in pagination and typographic detail.

Please cite the original version. 
DR THOMAS BERGHOLT (Orcid ID : 0000-0002-7284-6094)

PROFESSOR FINN EGIL SKJELDESTAD (Orcid ID : 0000-0001-9875-4991)

DR KARIN KÄLLÉN (Orcid ID : 0000-0001-5765-2630)

DR AURA PYYKÖNEN (Orcid ID : 0000-0001-9968-6660)

Article type : Original Research Article

Maternal age and risk of cesarean section in women with induced labor at term - a Nordic register-based study

Thomas BERGHOLT ${ }^{1}$, Finn Egil SKJELDESTAD ${ }^{2}$, Aura PYYKÖNEN³, Steen C.

RASMUSSEN ${ }^{1}$, Anna-Maija TAPPER ${ }^{4,5}$, Ragnheiður I. BJARNADÓTTIR ${ }^{6-8}$, Alexander SMÁRASON ${ }^{7}$, Birna B. MÁSDÓTTIR ${ }^{8}$, Kari KLUNGSØYR ${ }^{9,10}$, Susanne ALBRECHTSEN ${ }^{10,11}$, Karin KÄLLÉN ${ }^{12,13}$, Mika GISSLER ${ }^{14,15}$, Ellen Christine Leth LØKKEGAARD ${ }^{1}$

1. Clinical Research Unit, Department of Obstetrics and Gynecology, North Zeeland Hospital, University of Copenhagen, Hillerød, Denmark.

2. Department of Community Medicine, Faculty of Health Sciences, UiT the Arctic University of Norway, Tromsø, Norway

This article has been accepted for publication and undergone full peer review but has not been through the copyediting, typesetting, pagination and proofreading process, which may lead to differences between this version and the Version of Record. Please cite this article as doi: 10.1111/AOGS.13743

This article is protected by copyright. All rights reserved 
3. Department of Obstetrics and Gynecology, Helsinki University Hospital, Helsinki, Finland

4. Hyvinkää Hospital, Hyvinkää, Finland

5. University of Helsinki, Helsinki, Finland

6. The Icelandic Birth Registry, Akureyri, Iceland

7. Institute of Health Science Research, University of Akureyri, Akureyri, Iceland

8. Landspitali University Hospital, Reykjavik, Iceland

9. Division of Mental and Physical Health, Norwegian Institute of Public Health, Bergen, Norway

10. Department of Global Public Health and Primary Care, University of Bergen, Bergen, Norway

11. Haukeland University Hospital, Bergen, Norway

12. Swedish National Board of Health and Welfare, Stockholm, Sweden

13. University of Lund, Lund, Sweden

14. Finnish Institute for Health and Welfare THL, Helsinki, Finland

15. Department of Neurobiology, Care Sciences and Society, Karolinska Institute, Stockholm, Sweden

\section{Corresponding Author:}

Ellen Løkkegaard

Department of Obstetrics and Gynecology, North Zeeland Hospital, University of Copenhagen, Dyrehavevej 29, 3400 Hillerød, Denmark

Email: Ellen.Christine.Leth.Loekkegaard@regionh.dk 


\section{Conflicts of interest}

None

\section{Funding}

The study has been funded by the Nordic Federation of Societies of Obstetrics and Gynecology (NFOG) Fund.

\section{ABSTRACT}

Introduction: Over the last decades, induction of labor has increased in many countries along with increasing maternal age. We assessed the effects of maternal age and labor induction on cesarean section at term among nulliparous and multiparous women without previous cesarean section. Material and methods: We performed a retrospective national registry-based study from Denmark, Finland, Iceland, Norway and Sweden including 3398586 deliveries between 2000 and 2011. We investigated the impact of age on cesarean section among 196220 nulliparous and 188 158 multiparous women whose labor was induced, had single cephalic presentation at term and no previous cesarean section. Confounders comprised country, time-period and gestational age. Results: In nulliparous women with induced labor the rate of cesarean section increased from $14.0 \%$ in women less than 20 years of age to $39.9 \%$ in women 40 years and older. Compared to women aged 25-29 years, the corresponding relative risk were 0.60 (95\% confidence interval (CI); 0.57 to 0.64$)$ and $1.72(95 \% \mathrm{CI} ; 1.66$ to 1.79$)$. In multiparous induced women the risk of cesarean section was $3.9 \%$ in women less than 20 years rising to $9.1 \%$ in women 40 years and older. 
Compared to women aged 25-29 years, the relative risk were $0.86(95 \% \mathrm{CI} ; 0.54$ to 1.37$)$ and 1.98 ( $95 \%$ CI; 1.84 to 2.12 ), respectively. There were minimal confounding effects of country, timeperiod and gestational age on risk for cesarean section. Conclusions: Advanced maternal age is associated with increased risk of cesarean section in women undergoing labor induction with a single cephalic presentation at term without a previous cesarean section. The absolute risk of cesarean section is 3-5 times higher across 5-year age groups in nulliparous relative to multiparous women having induced labor.
Abbreviations:
CS cesarean section
CI confidence interval
$\mathrm{RR}$ relative risk

\section{Keywords}

Maternal age, induction of labor, cesarean section, birth register

\section{Key message}

Induction and cesarean section rates increased by age in both nulli- and multiparous women in all Nordic countries over the years 2001 through 2011. 


\section{INTRODUCTION}

For many decades maternal age at childbirth has increased in Europe (1) and the USA (2). Data from Nordic Perinatal Statistics confirms the international trends of increasing maternal age in all the Nordic countries (3). Along with increasing maternal age, the overall rate of labor inductions has doubled from year 2000 to 2012 in Denmark (4) and from 2003 to 2013 in Norway (5). In Sweden, induction of post-term pregnancies increased from $28 \%$ in 1992 to $46 \%$ in 2006 (4).

A systematic review of randomized controlled trials comparing post-term spontaneous onset of labor with induction at or beyond term concluded on a significantly decreased risk of perinatal death as well as a reduction in cesarean section (CS) among women having induced labor (5). Furthermore, randomized controlled trials have found induction of labor associated with improved 
maternal outcomes for women with mild hypertensive disorders beyond 37 weeks of gestation (6), and with reduced risk of shoulder dystocia and related morbidity in large-for-dates fetuses compared to expectant management (7).

There is a general concern about increasing CS rates world-wide (8). Delivery by CS has implication on postoperative maternal morbidity and complications in subsequent pregnancies (9, 10). The World Health Organization has recently re-evaluated their strategy regarding the optimal CS rate. They state that CS should only be performed in pregnancies that benefit fetal and maternal health, and this may vary around the world according to obstetric competence and organization of labor care (11). Physiological changes in the pregnant population including increasing maternal age $(1,12)$ and body mass index $(13,14)$, combined with an increasing proportion of women with prior CS (15), and multiple pregnancies (16), have been associated with increasing risk for CS in subsequent pregnancies. CS rates have been reported from 3.5\% in Africa to $29.2 \%$ in Latin America and the Caribbean (17), and 32.0\% in the USA (18). The overall CS rate in the Nordic countries was $17.0 \%$ from 2000 to 2011 , ranging from $15.7 \%$ in Norway to $19.2 \%$ in Denmark (15). National variation in CS rates in the Nordic countries was far less than reported elsewhere (19).

The aims of the present study was to assess the effects of maternal age and labor induction on risk of CS at term among nulliparous and multiparous women without previous CS in the Nordic countries over a 12-year time-period.

\section{MATERIAL AND METHODS}

The study was initiated by the Nordic Robson Research collaboration $(15,20)$ based on national medical register data from the five Nordic countries, merged and processed in Statistics Denmark, Copenhagen. Selected variables were harmonized across birth register in the merged database. Maternal age was defined as the difference in completed years between date of delivery and maternal date of birth, and categorized into six groups $(<20,20-24,25-29,30-34,35-39, \geq 40$ years). Parity and previous CS were defined as the highest number based on information in the 
register or maternal information provided at first delivery. Gestational age was with few exceptions estimated from ultrasound screening of bi-parietal diameter in second trimester and categorized into three categories $(37-38,39-41, \geq 42$ weeks). Included in the original database were women who delivered after the $22^{\text {nd }}$ gestational week, or, if gestational age was missing, women who gave birth to infants with a birth weight of $500 \mathrm{~g}$ or more. Start of delivery was defined as spontaneous onset of birth, induction or CS. Emergency CS's encompassed all CS's not reported as elective. Mode of delivery comprised spontaneous vaginal delivery, instrumental vaginal delivery (vacuum extraction or forceps) or CS. Data on presenting part of the baby at delivery was categorized into cephalic, breech presentation, or transverse lie. We categorized three-year periods as 2000-02, 2003-05, 2006-08 and 2009-11.

We have used the Robson classification system, a method of stratifying delivering women into ten clinically relevant groups, making comparison of interventions and outcomes within groups more clinically relevant. In the Robson system groups are mutually exclusive (21). In this study, we have included Robson groups 1 to 4 . Groups 1 and 2 comprise nulliparous women with a baby in single cephalic presentation after 36 weeks of gestation. Group 1 includes women in spontaneous labor (R1) and group 2 women having labor induced (R2a) or pre-labor CS (R2b). Groups 3 and 4 comprise multiparous women with a baby in single cephalic presentation after 36 weeks of gestation and no history of CS. Group 3 includes multiparous women in spontaneous labor (R3) and group 4 multiparous women having labor induced (R4a) or pre-labor CS (R4b)

\section{Statistical analyses}

We estimated proportions of nulliparous women having pre-labor CS (R2b/(R1+R2)), proportion of women having induction of labor (R2a/(R1+R2)), and overall CS rate in nulliparous women $(\mathrm{CS}$ in $(\mathrm{R} 1+\mathrm{R} 2 \mathrm{a}) /(\mathrm{R} 1+\mathrm{R} 2))$. Similarly, proportions of multiparous women having pre-labor $\mathrm{CS}$ $(\mathrm{R} 4 \mathrm{~b} /(\mathrm{R} 3+\mathrm{R} 4))$, induction of labor $(\mathrm{R} 4 \mathrm{a} /(\mathrm{R} 3+\mathrm{R} 4))$, and overall $\mathrm{CS}$ rate in multiparous women with no history of CS $(\mathrm{CS}$ in $(\mathrm{R} 3+\mathrm{R} 4 \mathrm{a}) /(\mathrm{R} 3+\mathrm{R} 4))$ were calculated.

We performed multiple unconditioned logistics regressions models to estimate odds ratio of CS in induced nulliparous (R2a) and multiparous (R4a) women, and in nulliparous (R1) and multiparous (R3) women having spontaneous onset of labor. Maternal age was main exposure, while country, time-period and gestational age were considered confounding factors. Results are presented as 
proportions (rates) in percentages and in relative risks (RR's) with 95\% confidence intervals (CI). IBM SPSS Statistics Version 24 (IBM Corp., Armonk, USA) was used for the statistical analyses.

\section{Ethical approval}

The Danish Data protection Agency administered the Danish participation in the study (reference NOH-2016-006), and the Regional Committee for Medical and Health Research Ethics South-East C (REK Sør-Øst 2010/3256) assessed the Norwegian participation. The Directorate of Health in Iceland, THL Finnish Institute of Health and Welfare in Finland and the Swedish National Board of Health and Welfare gave their authorizations for using anonymized data.

\section{RESULTS}

From January 2000 to December 2011 there were in total 3398586 deliveries in the five Nordic countries. Nulliparous women with a single baby in cephalic presentation at term included 1294 452 mothers (R1+R2). Of these 40572 (3.1\%) women had pre-labor CS (R2b), 196220 (15.2\%) had labor induced (R2a) and 1057660 (81.7\%) had spontaneous onset of labor (R1). Multiparous women with a single baby in cephalic presentation at term, with no previous CS, included 1471 057 mothers (R3+R4). Of these 40885 (2.8\%) women had pre-labor CS (R4b), 188158 (12.8\%) had labor induced (R4a) and 1242014 (84.4\%) spontaneous onset of labor (R3).

Over the 12-year study period the proportion of women having labor induction increased from $11.8 \%$ to $20.1 \%$ in nulliparous and from $9.9 \%$ to $16.8 \%$ in multiparous women. The increases among nulliparous as well as multiparous women were consistent across countries and age groups.

In the multivariate unconditional logistic regression analysis, country, time-period and gestational age had no confounding effect on the age-specific or overall estimates of CS in neither nulliparous nor multiparous women having labor induced (data not presented). Consequently, we only presented crude estimates and RR in Table 3. The age-specific estimates of induction on CS were consistent and relatively robust in almost all analyses of time-period and country (no interactions). 
The temporal relations between proportions of women having pre-labor CS, induction of labor, and overall CS rates by parity are displayed in Figure 1. The proportions of nulliparous as well as multiparous women having pre-labor CS were relatively low and stable over time with estimates varying from 2.0 to $3.4 \%$. The overall $\mathrm{CS}$ rate in nulliparous women $(\mathrm{CS} / \mathrm{R} 1+\mathrm{R} 2)$ increased from $12.4 \%$ in 2000 to $14.9 \%$ in 2006 and remained stable thereafter. In the multiparous women $(\mathrm{CS} / \mathrm{R} 3+\mathrm{R} 4)$ the CS rate varied from $4.2 \%$ in 2000 , a peak of $5.6 \%$ in 2007 , to $5.1 \%$ in 2011 .

Crude rates of CS in induced nulliparous women at term (R2a) by age and overall (R2a) are displayed in Table 1 . The overall CS rate was $25.0 \%$ increasing consistently from $14 \%$ in the youngest to $40 \%$ in the oldest age group. There were small variations in the crude CS rates by age and in total between nulliparous women in R2a the five Nordic countries. Age-stratified analysis by time-period and gestational age found consistently increasing CS rates from the youngest to the oldest age group across all subsets of analyses.

In the same manner, number of women under risk and crude rates of CS in induced multiparous women with no previous CS (Robson 4a) are shown in Table 2. The overall CS rate in the Robson 4a group was 5.5\%. The risk of CS increased with age in all countries. Finland had lower agespecific CS rates and a lower overall crude CS compared to the other Nordic countries. Moreover, the crude CS rates ranged from 2.4\% (Finland) to $4.7 \%$ (Iceland) in women 20-24 years of age, and from $5.2 \%$ (Finland) and $10.9 \%$ (Sweden) in women 40 years or older.

Across age groups, the RR of CS in nulliparous women with induced labor (R2a) increased significantly by a five-fold from 0.60 (95\% CI: $0.57-0.64)$ in women below 20 years of age to 1.72 (95\% CI:1.66-1.79) in women 40 years or above (Table 3). The same pattern was observed in nulliparous women with spontaneous onset of labor (R1) with RRs increasing from 0.57 (95\% CI:0.55-0.60) in the youngest group to 2.50 (95\% CI: 2.37-2.64) in women 40 years or older.

In the 432 multiparous women, younger than 20 years, with induced labor (R4a) the crude CS rate was 3.9\%. The CS rate increased from 3.2\% in women aged $20-24$ years to $9.1 \%$ in women 40 years or above. The RR increased from 0.70 (95\% CI: 0.63-0.77) in women 20-24 years to 1.98 (95\% CI: 1.84-2.12) in women 40 years or above. 
The absolute risk of CS in both nulliparous and multiparous women with induced labor (R2a/R4a) compared to the respective women with spontaneous onset of labor (R1/R3) was 1.90 to 2.98 times higher among nulliparous and 2.28 to 2.80 higher among nulliparous women. (Table 3 ).

\section{DISCUSSION}

The main findings from this study were an increasing incidence of induction of labor and stable rates of CS before onset of labor in the Nordic countries, from 2000 to 2011 in both nulliparous and multiparous women, with a single baby in single cephalic presentation at term, and no previous CS. In addition, we found that increasing maternal age was associated with increasing RR of CS in both nulliparous and multiparous women. The RR of CS was 2-3 times higher in each age group among women having induced relative spontaneous onset of labor. These estimates enable Nordic obstetricians and midwifes to inform pregnant women at term, with a single baby in cephalic presentation and no previous CS, about their average risk of CS if they are having labor induced.

Furthermore, we found an association between rising induction rates to $15 \%$ in nulliparous women $(\mathrm{R} 1+\mathrm{R} 2)$ and $13 \%$ in multiparous women $(\mathrm{R} 3+\mathrm{R} 4)$ from 2000 to 2007 and an increasing risk of overall CS to $15.0 \%$ and $5.1 \%$ respectively during the same period. When the induction rates increased further to $20.1 \%$ and $16.8 \%$ in 2011 , the respective overall CS rates remained stable at $14.9 \%$ and $5.1 \%$. These findings indicate that the risk of CS might be unaffected above a certain proportion of women having labor induced among nulliparous as well as multiparous women without a previous CS. Our findings among nulliparous women is supported by the findings of a large randomized controlled trial of induction of labor in 6104 American low-risk women between $39+0$ and 39+4 days of gestation, the ARRIVE study (22). The authors found a decreased RR of CS (RR 0.84 (95\% CI:0.76-0.93)) in women randomized to labor induction compared to women awaiting for spontaneous onset of labor. Low risk nulliparous women are currently not having labor induced before term in the Nordic countries, but if they are going to be in the future, the results from the ARRIVE suggests that there may be an associated reduced overall CS rate.

A major strength of the study is the large sample size with national data from the five Nordic countries. Limitations of the study are the observational design combined with lack of data for 
body mass index, more detailed information of indications for induction, and the Bishop score at time for induction. However, a systematic review from 2013 concluded that Bishop score is a poor predictor of outcome of induced labor including risk of CS, and the authors advocated not to use Bishop score to decide whether to induce labor or not (23).

Cheng and colleagues published an observational study of 442003 low risk nulliparous women with a baby in single cephalic presentation delivering between 39 and 42 weeks of gestation comparing induction of labor with expectant management (23). They found a lower risk of CS $(\mathrm{OR}=0.90,(95 \% \mathrm{CI} 0.88$ to 0.91$))$ if induced at 39 weeks of gestation compared to expectant management (24). In their low-risk nulliparous population the proportion aged 35 years or more, was $7.3 \%$ compared to $13.4 \%$ in our population. As high maternal age is associated with CS and assisted vaginal delivery $(25,26)$, these findings underline the importance of maternal age differences in study populations when comparing results of obstetric operative intervention in obstetrics across studies. In a randomized controlled trial of induction of labor relative expectant management in nulliparous women 35 years or older no significant differences in CS rates were found (32.2\% relative $32.8 \%$ ) (27). Their CS rate in the induction group is similar with the CS rate of $34.3 \%$ in nulliparous women 35 to 39 years of age in the present study. In a meta-analysis of randomized controlled trials of induction of labor at full term in uncomplicated singleton gestations, Saccone and Berghella reported a CS rate of $25.5 \%$ among nulliparous women with labor induced (28) similar to our findings (25.0\%).

Beside the increased use of induction of labor in post-term and hypertensive pregnancies, other factors as institutional culture in obstetric practice and growing patient involvement in the decision-making process can influence the use of induction of labor. In a qualitative study, midwives and doctors from ten Australian hospitals expressed a large variation in clinical decision-making for induction of labor. (29). In addition, the authors found that hospitals having senior midwifes or midwife managers, serving as gatekeepers with the authority to question the indication for induction, had lower rates of induction of labor. A Dutch interview study of doctors and midwifes found that medical indications as pre-eclampsia and post-term pregnancy were the most important factors in the decision for induction of labor (30). Together, these findings indicate the need for continuous audit of the rates and indications for induction of labor and CS at each delivery unit. This is important for surveillance of institutional standards regarding induction of labor and to provide institutional data for information to the pregnant women. 


\section{CONCLUSION}

The risk of CS increases with increasing maternal age after both induced and spontaneous onset of labor in nulliparous and multiparous women without previous CS. In all age groups, the risk of CS is considerably higher following induced labor. The findings provide a knowledge basis which can help to inform women at term about their average risk of CS associated with induction of labor and help these women in the decision-making process. Women are entitled to be informed of benefits and risks related to the procedure, including risk of CS, when induction of labor is considered.

\section{References}

1. European Commission. Eurostat. Mean age of women at childbirth. Available online at: [Available from:

http://ec.europa.eu/eurostat/tgm/table.do?tab=table\&init=1\&language=en\&pcode=tps00017\&plugin=1 (Accessed April 12, 2019).

2. Laughon SK, Branch DW, Beaver J, Zhang J. Changes in labor patterns over 50 years. Am J Obstet Gynecol. 2012;206(5):419.e1-9.

3. Heino A GM. Nordic perinatal statistics 2016. Available online at: [updated 5th March 2018. Available from: http://www.julkari.fi/bitstream/handle/10024/136095/Tr05_08.pdf?sequence=1 (Accessed April 11, 2019)

4. Roos N, Sahlin L, Ekman-Ordeberg G, Kieler H, Stephansson O. Maternal risk factors for postterm pregnancy and cesarean delivery following labor induction. Acta Obstet Gynecol Scand. 2010;89(8):100310.

5. Middleton P, Shepherd E, Crowther CA. Induction of labour for improving birth outcomes for women at or beyond term. Cochrane Database Syst Rev. 2018;5:CD004945.

6. Koopmans $\mathrm{CM}$, Bijlenga $\mathrm{D}$, Groen $\mathrm{H}$, et al. Induction of labour versus expectant monitoring for gestational hypertension or mild pre-eclampsia after 36 weeks' gestation (HYPITAT): a multicentre, openlabel randomised controlled trial. Lancet . 2009;374(9694):979-88.

7. Boulvain M, Senat MV, Perrotin F, et al. Induction of labour versus expectant management for large-for-date fetuses: a randomised controlled trial. Lancet. 2015;385(9987):2600-5.

This article is protected by copyright. All rights reserved 
8. WHO Statement on Caesarean Section Rates. Available online at: [Available from:

http://www.who.int/reproductivehealth/publications/maternal_perinatal_health/cs-statement/en/ (Accessed April 12, 2019).

9. Farchi S, Polo A, Franco F, Di Lallo D, Guasticchi G. Severe postpartum morbidity and mode of delivery: a retrospective cohort study. Acta Obstet Gynecol Scand. 2010;89(12):1600-3.

10. Silver RM, Landon MB, Rouse DJ, et al. Maternal morbidity associated with multiple repeat cesarean deliveries. Obstet Gynecol. 2006;107(6):1226-32.

11. Betran AP, Torloni MR, Zhang JJ, Gulmezoglu AM. WHO Statement on Caesarean Section Rates. BJOG . 2016;123(5):667-70.

12. Herstad L, Klungsoyr K, Skjaerven R, et al. Maternal age and emergency operative deliveries at term: a population-based registry study among low-risk primiparous women. BJOG. 2015;122(12):164251.

13. Bergholt T, Lim LK, Jørgensen JS, Robson MS. Maternal body mass index in the first trimester and risk of cesarean delivery in nulliparous women in spontaneous labor. Am J Obstet Gynecol. 2007;196: 163.e1-5.

14. Fyfe EM, Anderson NH, North RA, et al. Risk of first-stage and second-stage cesarean delivery by maternal body mass index among nulliparous women in labor at term. Obstet Gynecol. 2011;117(6):131522.

15. Pyykonen A, Gissler M, Lokkegaard E, et al. Cesarean section trends in the Nordic Countries - a comparative analysis with the Robson classification. Acta Obstet Gynecol Scand. 2017;96(5):607-16.

16. Ananth CV, Chauhan SP. Epidemiology of twinning in developed countries. Sem Perinatol. 2012;36(3):156-61.

17. Betran AP, Merialdi M, Lauer JA, et al. Rates of caesarean section: analysis of global, regional and national estimates. Paediatr Perinat Epidemiol. 2007;21(2):98-113.

18. Martin JA HB, Osterman JK, Driscoll AK, Mathews MS. Births: Final Data for 2015. Natl Vital Stat Rep. 2017;66:1.

19. Plevani C, Incerti M, Del Sorbo D, et al. Cesarean delivery rates and obstetric culture - an Italian register-based study. Acta Obstet Gynecol Scand. 2017;96(3):359-65.

20. Rossen J, Klungsoyr K, Albrechtsen S, et al. Can oxytocin augmentation modify the risk of epidural analgesia by maternal age in cesarean sections? Acta Obstet Gynecol Scand. 2018;97(7):872-9.

21. Torloni MR, Betran AP, Souza JP, et al. Classifications for cesarean section: a systematic review. PloS One. 2011;6(1):e14566.

This article is protected by copyright. All rights reserved 
22. Grobman WA, Rice MM, Reddy UM, et al. Labor Induction versus Expectant Management in LowRisk Nulliparous Women. N Engl J Med. 2018;379(6):513-23.

23. Kolkman DG, Verhoeven CJ, Brinkhorst SJ, et al. The Bishop score as a predictor of labor induction success: a systematic review. Am J Perinatol. 2013;30(8):625-30.

24. Cheng YW, Kaimal AJ, Snowden JM, Nicholson JM, Caughey AB. Induction of labor compared to expectant management in low-risk women and associated perinatal outcomes. Am J Obstet Gynecol. 2012;207(6):502.e1-8.

25. Wang $Y$, Tanbo T, Abyholm T, Henriksen T. The impact of advanced maternal age and parity on obstetric and perinatal outcomes in singleton gestations. Arch Gynecol Obstet. 2011;284(1):31-7.

26. Ankarcrona V, Altman D, Wikstrom AK, Jacobsson B, Brismar Wendel S. Delivery outcome after trial of labor in nulliparous women 40 years or older-A nationwide population-based study. Acta Obstet Gynecol Scand. 2019;98(9):1195-203.

27. Walker KF, Bugg GJ, Macpherson M, et al. Randomized Trial of Labor Induction in Women 35 Years of Age or Older. New Engl J Med. 2016;374(9):813-22.

28. Saccone G, Berghella V. Induction of labor at full term in uncomplicated singleton gestations: a systematic review and metaanalysis of randomized controlled trials. Am J Obstet Gynecol. 2015;213(5):629-36.

29. Nippita TA, Porter M, Seeho SK, Morris JM, Roberts CL. Variation in clinical decision-making for induction of labour: a qualitative study. BMC Pregnancy Childbirth. 2017;17(1):317.

30. Vellekoop J, Vrouenraets FP, van der Steeg JW, Mol BW, Roumen FJ. Indications and results of labour induction in nulliparous women: an interview among obstetricians, residents and clinical midwives. Eur J Obstet Gynecol Reprod Biol. 2009;146(2):156-9.

This article is protected by copyright. All rights reserved 


\section{Figure and table legends}

Figure 1. The proportion of women having cesarean section (CS) before onset of labor $\mathrm{R} 2 \mathrm{~b} /(\mathrm{R} 1+\mathrm{R} 2)$ and $\mathrm{R} 4 \mathrm{~b} /(\mathrm{R} 3+\mathrm{R} 4)$, having labor induced $\mathrm{R} 2 \mathrm{a} /(\mathrm{R} 1+\mathrm{R} 2)$ and $\mathrm{R} 4 \mathrm{a} /(\mathrm{R} 3+\mathrm{R} 4)$ and $\mathrm{CS}$ rates in women with spontaneous and induced labor $\mathrm{CS} /(\mathrm{R} 1+\mathrm{R} 2 \mathrm{a})$ and $\mathrm{CS} /(\mathrm{R} 3+\mathrm{R} 4 \mathrm{a})$ by parity. Nordic countries, 2000-2011.

Table 1. Total number of nulliparous women with a singleton infant in cephalic presentation at term and with induced labor (Robson group 2a), displayed with the cesarean section (CS) rate (\%), by maternal age, country, time period, and gestational age. Nordic countries, 2000-2011.

Table 2. Total number of multiparous women without previous CS, with a singleton infant in cephalic presentation at term and with induced labor (Robson group 4a), displayed with the cesarean section (CS) rate $(\%)$, by maternal age, country, time period, and gestational age. Nordic countries, 2000-2011.

Table 3. Total number of women with a singleton infant in cephalic presentation at term, no previous cesarean section (CS) and with induced or spontaneous onset of labor (Robson group $1+2 \mathrm{a}$ and Robson group $3+4 \mathrm{a})$, displayed with number $(\mathrm{N})$, CS rate $(\%)$ and relative risk (RR) with $95 \%$ confidence intervals (CI), by maternal age and parity. In addition, RR with $95 \%$ CI of $\mathrm{CS}$ in women having induced labor compared to women with spontaneous onset of labor is presented. Nordic countries, 2000-2011. 
Table 1.

Total number of nulliparous women with a singleton infant in cephalic presentation at term and with induced labor (R2a), along with the cesarean section rate (\%), by maternal age, country, time period, and gestational age. Shown for the Nordic countries, $2000-2011$.

\begin{tabular}{|c|c|c|c|c|c|c|c|c|c|c|c|c|c|c|c|}
\hline \multirow[t]{2}{*}{ Maternal age } & & \multicolumn{2}{|c|}{$<20$} & \multicolumn{2}{|c|}{$20-24$} & \multicolumn{2}{|c|}{$25-29$} & \multicolumn{2}{|c|}{$30-34$} & \multicolumn{2}{|c|}{$35-39$} & \multicolumn{2}{|c|}{$>40$} & \multicolumn{2}{|c|}{ Total } \\
\hline & & $\mathrm{n}$ & $\mathrm{CS} \%$ & $\mathrm{n}$ & $\mathrm{CS} \%$ & $\mathrm{n}$ & $\mathrm{CS} \%$ & $\mathrm{n}$ & $\mathrm{CS} \%$ & $\mathrm{n}$ & $\mathrm{CS} \%$ & $\mathrm{n}$ & $\mathrm{CS} \%$ & $\mathrm{n}$ & $\mathrm{CS} \%$ \\
\hline & Total & 7285 & (14.0) & 38932 & $(18.7)$ & 68987 & (23.2.) & 54752 & $(28.2)$ & 21484 & (34.3) & 4780 & (39.9) & 196220 & (25.0) \\
\hline \multirow[t]{4}{*}{ Country } & Denmark & 1222 & (13.5) & 7478 & (17.9) & 16530 & (23.3) & 12023 & (27.4) & 4298 & (32.9) & 873 & $(38.3)$ & 42424 & (24.5) \\
\hline & Finland & 2418 & (12.4) & 10593 & $(17.0)$ & 15460 & $(20.4)$ & 11097 & $(25.5)$ & 4446 & $(31.4)$ & 1034 & $(38.8)$ & 45048 & (21.9) \\
\hline & Norway & 1668 & (14.6) & 8683 & (18.6) & 14532 & $(22.4)$ & 10707 & (25.7) & 3935 & $(32.2)$ & 809 & $(37.2)$ & 40334 & (23.4) \\
\hline & Sweden & 1697 & $(15.9)$ & 11086 & (20.4) & 21188 & $(25.5)$ & 20349 & (31.3) & 8557 & $(37.5)$ & 1994 & $(42.4)$ & 64871 & (28.3) \\
\hline \multirow[t]{4}{*}{ Time period } & $2000-2002$ & 1654 & $(12.9)$ & 8052 & (16.8) & 13986 & $(22.6)$ & 9577 & (26.7) & 3317 & (33.3) & 574 & $(36.6)$ & 37160 & $(23.2)$ \\
\hline & $2003-2005$ & 1669 & (12.4) & 8753 & (18.8) & 16310 & $(23.0)$ & 12889 & (28.3) & 4768 & (33.7) & 883 & $(40.7)$ & 45272 & $(24.8)$ \\
\hline & 2006-2008 & 1863 & $(15.2)$ & 9834 & (19.6) & 17603 & $(24.3)$ & 15019 & $(29.8)$ & 6003 & $(35.5)$ & 1399 & $(40.2)$ & 51721 & (26.4) \\
\hline & $2009-2011$ & 2099 & (14.9) & 12293 & (19.2) & 21088 & (22.7) & 17267 & (27.4) & 7396 & (34.3) & 1924 & $(40.3)$ & 62067 & (25.0) \\
\hline \multirow[t]{3}{*}{ Gestational age } & $37+0$ to $38+6$ & 1477 & (13.4) & 7575 & (15.6) & 12492 & (19.4) & 8987 & $(22.6)$ & 3312 & $(27.2)$ & 665 & $(37.0)$ & 34508 & (20.2) \\
\hline & $39+0$ to $41+6$ & 4016 & $(12.8)$ & 21300 & $(17.8)$ & 36604 & $(21.8)$ & 28584 & $(26.5)$ & 11756 & $(33.2)$ & 3132 & (38.5) & 105392 & (23.7) \\
\hline & $>41+6$ & 1792 & $(17.0)$ & 10057 & (22.9) & 19891 & $(28.2)$ & 17181 & $(33.9)$ & 6416 & $(40.2)$ & 983 & $(46.4)$ & 56320 & (30.3) \\
\hline
\end{tabular}


Table 2.

Total number of multiparous women without previous CS, with a singleton infant in cephalic presentation at term and with induced labor (R4a), along with the CS rate (\%), by maternal age, country, time period, and gestational age. Shown for the Nordic countries, 2000-2011.

\begin{tabular}{|c|c|c|c|c|c|c|c|c|c|c|c|c|c|c|c|}
\hline \multirow[t]{2}{*}{ Maternal age } & & \multicolumn{2}{|c|}{$<\mathbf{2 0}$} & \multicolumn{2}{|c|}{$20-24$} & \multicolumn{2}{|c|}{$25-29$} & \multicolumn{2}{|c|}{$30-34$} & \multicolumn{2}{|c|}{$35-39$} & \multicolumn{2}{|c|}{$>40$} & \multicolumn{2}{|c|}{ Total } \\
\hline & & $\mathrm{n}$ & $\mathrm{CS} \%$ & $\mathrm{n}$ & $\mathrm{CS} \%$ & $\mathrm{n}$ & CS $\%$ & $\mathrm{n}$ & $\mathrm{CS} \%$ & $\mathrm{n}$ & $\mathrm{CS} \%$ & $\mathrm{n}$ & $\mathrm{CS} \%$ & $\mathrm{n}$ & $\mathrm{CS} \%$ \\
\hline & & 432 & (3.9) & 13329 & $(3.2)$ & 47629 & (4.6) & 71500 & $(5.2)$ & 43931 & $(6.9)$ & 11337 & $(9.1)$ & 188158 & $(5.5)$ \\
\hline \multirow[t]{4}{*}{ Country } & Denmark & 78 & $(5.1)$ & 2326 & (3.9) & 10267 & $(5.5)$ & 16772 & (5.6) & 9495 & (7.3) & 2116 & $(10.1)$ & 41054 & (6.1) \\
\hline & Finland & 165 & $(1.2)$ & 4928 & $(2.2)$ & 13802 & (2.9) & 17773 & (3.3) & 10783 & (4.6) & 3084 & $(5.2)$ & 50535 & (3.4) \\
\hline & Norway & 83 & $(2.4)$ & 2555 & $(4.3)$ & 9915 & (5.4) & 15179 & $(5.8)$ & 9004 & (7.9) & 2080 & $(10.6)$ & 38816 & $(6.3)$ \\
\hline & Sweden & 97 & $(8.2)$ & 3264 & (3.5) & 12596 & (5.1) & 20384 & $(6.1)$ & 13822 & (7.8) & 3821 & $(10.9)$ & 53984 & $(6.5)$ \\
\hline \multirow[t]{4}{*}{ Time-period } & $2000-2002$ & 75 & $(4.0)$ & 2856 & $(3.2)$ & 10389 & (5.1) & 14562 & $(5.2)$ & 8214 & (6.5) & 1901 & $(9.0)$ & 37997 & $(5.5)$ \\
\hline & 2003-2005 & 112 & $(4.5)$ & 3089 & $(3.0)$ & 11399 & $(4.7)$ & 16753 & $(5.5)$ & 10098 & $(7.5)$ & 2454 & $(8.9)$ & 43905 & $(5.8)$ \\
\hline & 2006-2008 & 119 & $(4.2)$ & 3356 & (3.6) & 11605 & $(4.6)$ & 18591 & (5.4) & 11522 & (7.1) & 3151 & $(10.0)$ & 48344 & $(5.8)$ \\
\hline & 2009-2011 & 126 & $(3.2)$ & 4028 & $(3.2)$ & 14236 & $(4.1)$ & 21594 & $(4.8)$ & 14097 & (6.6) & 3831 & (8.6) & 57912 & $(5.2)$ \\
\hline \multirow[t]{3}{*}{ Gestational age } & $37+0$ to $38+6$ & 117 & $(4.3)$ & 3630 & $(3.0)$ & 11779 & $(4.5)$ & 16798 & $(5.2)$ & 10278 & (7.1) & 2654 & $(9.0)$ & 45256 & $(5.5)$ \\
\hline & $39+0$ to $41+6$ & 252 & $(4.4)$ & 7436 & $(3.0)$ & 26706 & $(4.2)$ & 39959 & (4.9) & 25010 & $(6.3)$ & 6899 & $(8.5)$ & 106262 & $(5.2)$ \\
\hline & $>41+6$ & 63 & (1.6) & 2263 & (4.6) & 9144 & (5.7) & 14743 & (6.0) & 8643 & (8.4) & 1784 & (11.7) & 36640 & (6.7) \\
\hline
\end{tabular}


Table 3. Total number of women with a singleton infant in cephalic presentation at term, no previous cesarean section (CS) and with induced or spontaneous onset of labor (Robson group 1+2a and Robson group 3+4a), displayed with number $(\mathrm{N})$, CS rate $(\%)$ and relative risk (RR) with 95\% confidence intervals (CI), by maternal age and parity. In addition, RR with 95\% CI of CS in women having induced labor compared to women with spontaneous onset of labor is presented. Nordic countries, 2000-2011.

\begin{tabular}{|c|c|c|c|c|c|c|c|c|c|c|c|c|c|}
\hline \multirow{8}{*}{ 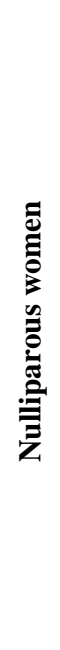 } & $\begin{array}{l}\text { Maternal } \\
\text { age }\end{array}$ & \multicolumn{5}{|c|}{ Induced labor (R2a) } & \multicolumn{5}{|c|}{ Spontaneous labor (R1) } & \multicolumn{2}{|c|}{ Induced/Spontaneous } \\
\hline & Years & Total & $\mathbf{N}$ & CS rate \% & $\mathbf{R R}$ & $95 \% \mathrm{CI}$ & Total & $\mathbf{N}$ & CS rate \% & $\mathbf{R R}$ & $95 \% \mathrm{CI}$ & $\mathbf{R} \mathbf{R}$ & $95 \% \mathrm{CI}$ \\
\hline & $<20$ & 7285 & 1020 & 14.0 & 0.60 & $(0.57-0.64)$ & 48463 & 2278 & 4.7 & 0.57 & $(0.55-0.60)$ & 2.98 & $(2.78-3.19)$ \\
\hline & $20-24$ & 38932 & 7280 & 18.7 & 0.81 & $(0.79-0.83)$ & 239336 & 15317 & 6.4 & 0.78 & $(0.77-0.80)$ & 2.92 & $(2.85-3.00)$ \\
\hline & $25-29$ & 68987 & 16005 & 23.2 & 1.00 & & 409618 & 33591 & 8.2 & 1.00 & & 2.83 & $(2.78-2.88)$ \\
\hline & $30-34$ & 54752 & 15440 & 28.2 & 1.22 & $(1.19-1.24)$ & 271596 & 29877 & 11.0 & 1.34 & $(1.32-1.36)$ & 2.56 & $(2.52-2.61)$ \\
\hline & $35-39$ & 21484 & 7369 & 34.3 & 1.48 & $(1.44-1.51)$ & 77338 & 11678 & 15.1 & 1.84 & $(1.81-1.88)$ & 2.27 & $(2.21-2.32)$ \\
\hline & $>40$ & 4780 & 1907 & 39.9 & 1.72 & $(1.66-1.79)$ & 11309 & 2375 & 21.0 & 2.50 & $(2.37-2.64)$ & 1.90 & $(1.81-2.00)$ \\
\hline \multirow{8}{*}{ 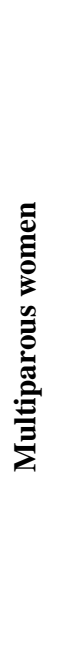 } & Maternal & \multicolumn{5}{|c|}{ Induced labor (R4a) } & \multicolumn{5}{|c|}{ Spontaneous labor (R3) } & \multicolumn{2}{|c|}{ Induced/Spontaneous } \\
\hline & Years & Total & $\mathbf{N}$ & CS rate \% & $\mathbf{R R}$ & $95 \% \mathrm{CI}$ & Total & $\mathbf{N}$ & CS rate \% & $\mathbf{R R}$ & $95 \% \mathrm{CI}$ & $\mathbf{R} \mathbf{R}$ & $95 \% \mathrm{CI}$ \\
\hline & $<20$ & 432 & 17 & 3.9 & 0.86 & $(0.54-1.37)$ & 3701 & 52 & 1.4 & 0.88 & $(0.67-1.15)$ & 2.80 & $(1.63-4.80)$ \\
\hline & $20-24$ & 13329 & 432 & 3.2 & 0.70 & $(0.63-0.77)$ & 104917 & 1364 & 1.3 & 0.81 & $(0.77-0.86)$ & 2.49 & $(2.24-2.77)$ \\
\hline & $25-29$ & 47569 & 2174 & 4.6 & 1.00 & & 357208 & 5716 & 1.6 & 1.00 & & 2.86 & $(2.72-3.00)$ \\
\hline & $30-34$ & 71500 & 3721 & 5.2 & 1.13 & $(1.07-1.19)$ & 494883 & 9403 & 1.9 & 1.19 & $(1.15-1.23)$ & 2.74 & $(2.64-2.84)$ \\
\hline & $35-39$ & 43931 & 3040 & 6.9 & 1.50 & $(1.42-1.58)$ & 245197 & 6375 & 2.6 & 1.63 & $(1.57-1.68)$ & 2.66 & $(2.55-2.78)$ \\
\hline & $>40$ & 11337 & 1032 & 9.1 & 1.98 & $(1.84-2.12)$ & 43575 & 1743 & 4.0 & 2.50 & $(2.37-2.64)$ & 2.28 & $(2.11-2.45)$ \\
\hline
\end{tabular}




\section{Figure 1:}

The proportion of women having CS before onset of labor R2b/(R1+R2) and R4b/(R3+R4), having labor induced R2a/(R1+R2) and $\mathrm{R} 4 \mathrm{a} /(\mathrm{R} 3+\mathrm{R} 4)$ and $\mathrm{CS}$ rates in women with spontaneous and induced labor CS/(R1+R2a) and CS/(R3+R4a) by parity.

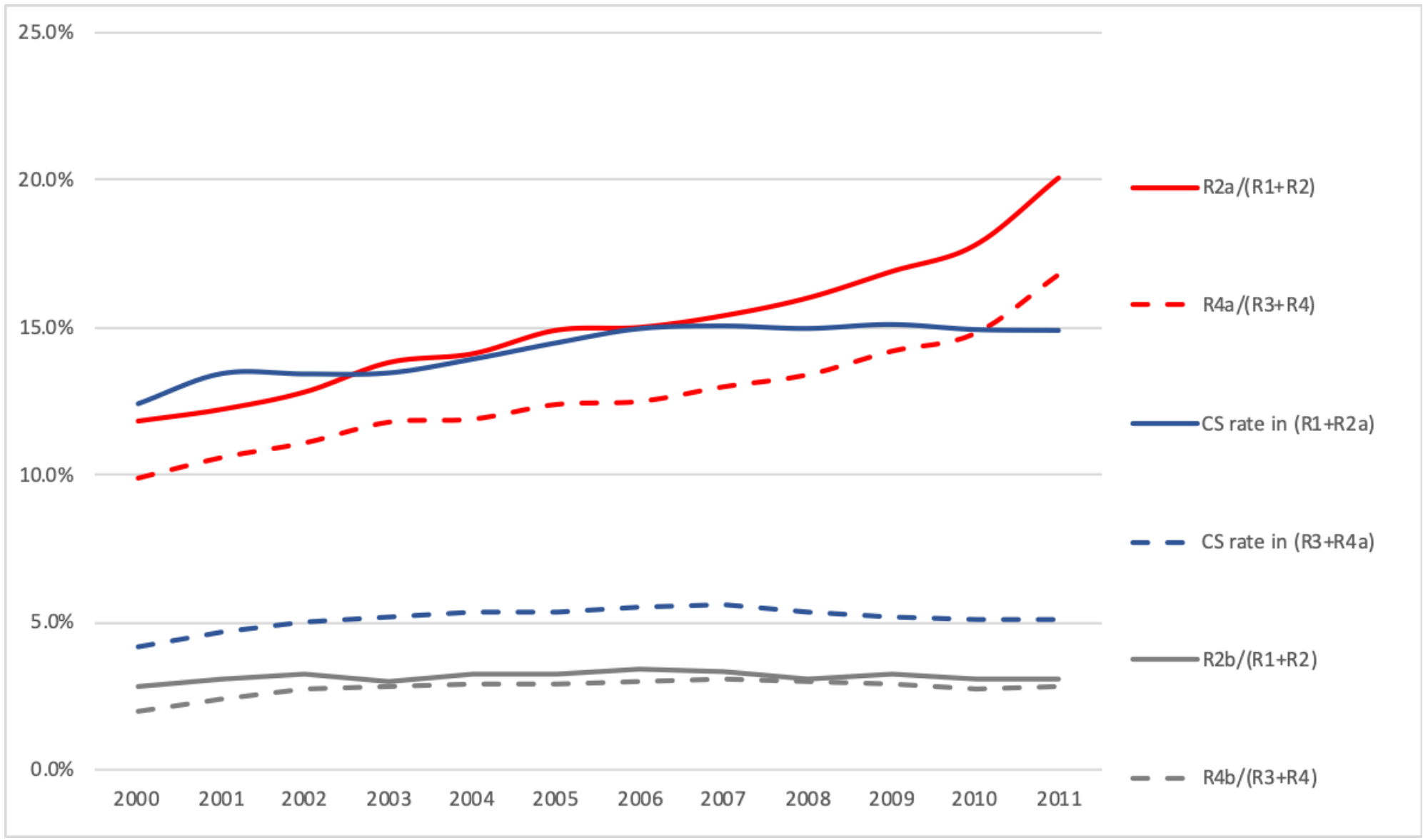

